\title{
Application Article \\ Design of RFID Reader Antenna for Exclusively Reading Single One in Tag Assembling Production
}

\author{
Chi-Fang Huang and Yi-Feng Huang \\ Graduate Institute of Communication Engineering, Tatung University, 40 Zhongshan, North Road, \\ Section 3, Taipei 104, Taiwan \\ Correspondence should be addressed to Chi-Fang Huang, ras@ttu.edu.tw
}

Received 5 December 2011; Revised 1 July 2012; Accepted 19 July 2012

Academic Editor: Dalia N. Elshiekh

Copyright ( 12012 C.-F. Huang and Y.-F. Huang. This is an open access article distributed under the Creative Commons Attribution License, which permits unrestricted use, distribution, and reproduction in any medium, provided the original work is properly cited.

\begin{abstract}
A design of RFID reader antenna including a fixture, which is equipped with a chip-attaching machine producing the RFID tags, is presented. Such an antenna is constrained to read exclusively one tag only for the purpose of functional check of the whole tag when it passes the reader antenna. Namely, the other neighbor tags on the same rolling band are ignored that time. A wideband microstrip antenna is designed and a fixture with shielding material is set up for such a reading constraint. Low efficiency with high return loss is allowed for this constraint, yet wideband is still a must to treat all possible produced tags used in different countries and areas in the world.
\end{abstract}

\section{Introduction}

Based on the diverse applications, different spectrum bands are allocated for RFID (radio frequency Identification) [1], for example, LF $(125-134.2 \mathrm{kHz}$ and $140-148.5 \mathrm{kHz})$ for animal control, $\mathrm{HF}(13.56 \mathrm{MHz})$ for electronic ticket and portal control, and UHF ( $868 \mathrm{MHz}-928 \mathrm{MHz})$ for logistics and fast portal control, and so forth. Most of the frequencies are located in the ISM (industrial, scientific, and medical) bands [1]. However, recently, the applications of RFID have been profoundly emphasized mainly because of the need of supply chains [2]. By proposing an international standard for the format of electronic data used for various items of goods, of which EPC (electronic product code) [3] is an example, and by establishing an infrastructure network of RFID worldwide, the products can be registered at once when they are shipped out from the factories (say, in China) and be released when they are checked out at the counter of a supermarket somewhere else (say, in USA). This is called "product tracking" and is being implemented in an "Internet of Thing (IOT)" [4].

The RFID tags [1] of supply chains are assumed to be very low cost, and also the RFID chips on them, since they are not reused after being attached on products. Therefore, taking the cost into account, usually the chips for tags do not afford to have a $100 \%$ quality assurance after foundry and package. Consequently, the risk of producing RFID tags with chips which probably do not work well does exist. Such a sort of tags with flaw is termed as dead or silent tags.

This kind of potential risk is not acceptable after the tag is made by attaching the chip on the tag antenna, especially for supply-chain purpose. Hence, the cost should be paid by carrying a functional check for tags one by one by an RFID reader after the chip is attached on the antenna as a tag, just as shown in Figure 1. That means, the production machine should be able to exclusively read the target tag under test only, and the other neighbor tags are not allowed to response when being read.

In this paper, a design of antenna plus a fixture is proposed. Considering the antenna's characteristics, the low efficiency of antenna with high return loss is allowed, since the antenna is so close to the tags under test, and tags are almost set in the near field range of reader antenna. In the present project, the return-loss criterion is set to be $-5 \mathrm{~dB}$. Anyway, the designed antenna for the assembling machine is still to work with a wideband to deal with all possible tags used in the world. For example, RFID and UHF bands are $866-869 \mathrm{MHz}$ in Europe, $902-928 \mathrm{MHz}$ in North 


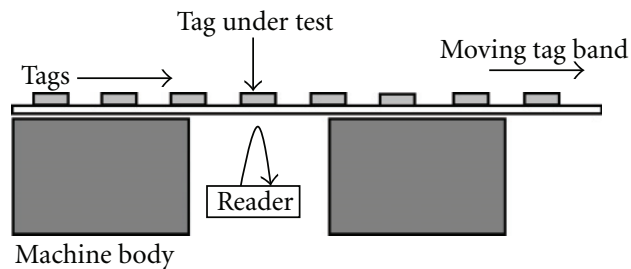

FIGURE 1: Setup for exclusively reading one single tag on a production machine.

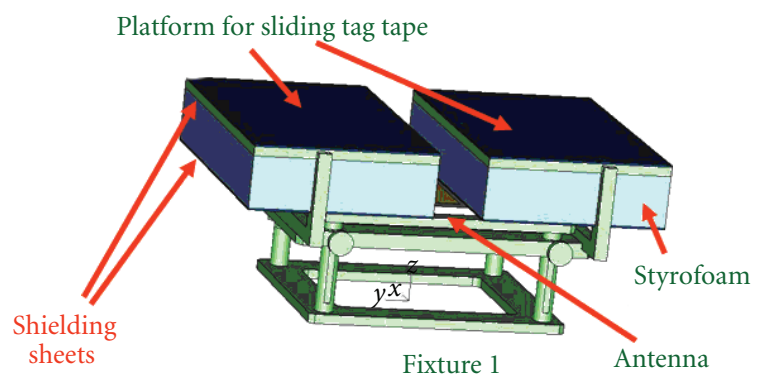

FIgURE 2: The proposed fixture.

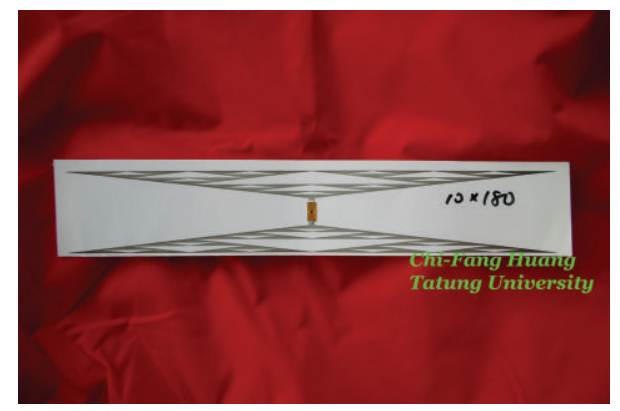

FIGURE 3: An RFID tag printed on a paper substrate [4].

and South America, and $950-956 \mathrm{MHz}$ in Japan and some Asian countries. The assigned RFID band is $902-928 \mathrm{MHz}$ in Taiwan. The wideband characteristics both of simulation and measurement of this antenna do cover these different bands.

Furthermore, this paper addresses a design of a fixture, see Figure 2, containing that reader antenna to meet the purpose mentioned above. This fixture is installed on a production machine of RFID tags. Measurement of the proximate-field strength on this fixture is done to verify the field distribution which is necessary for the present reading constraint. For reference, Figure 3 shows a typical RFID tag printed on a paper substrate, where the chip is attached at the center of tag antenna [4].

\section{Design of Reader Antenna}

Firstly, the reader antenna is designed. The concept of microstrip antenna [5] is adopted for this task. The reasons for choosing microstrip antenna are (a) low profile, so

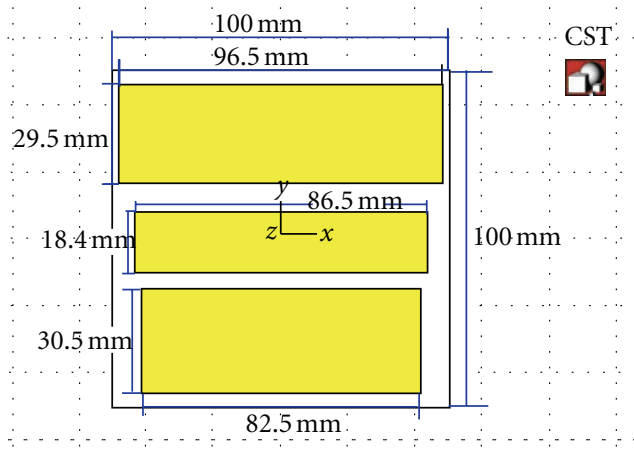

FIgURE 4: Simulation model of the wideband reader antenna.

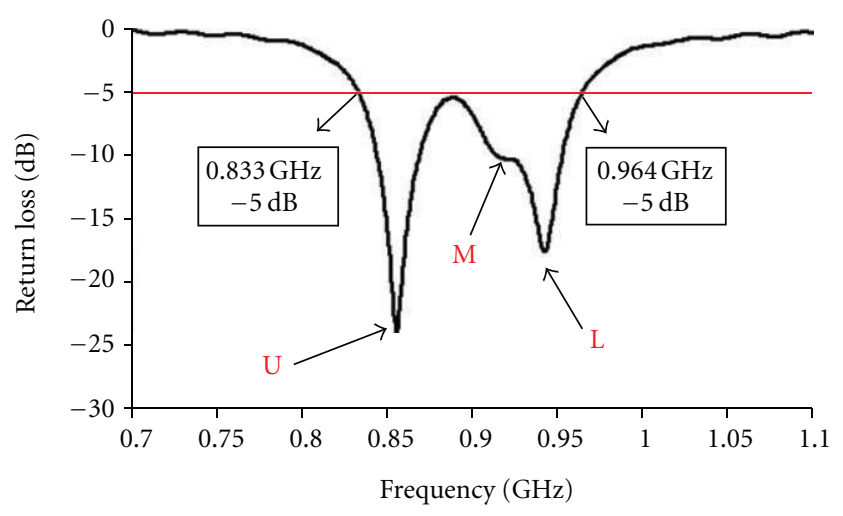

Figure 5: The simulated frequency response of return loss.

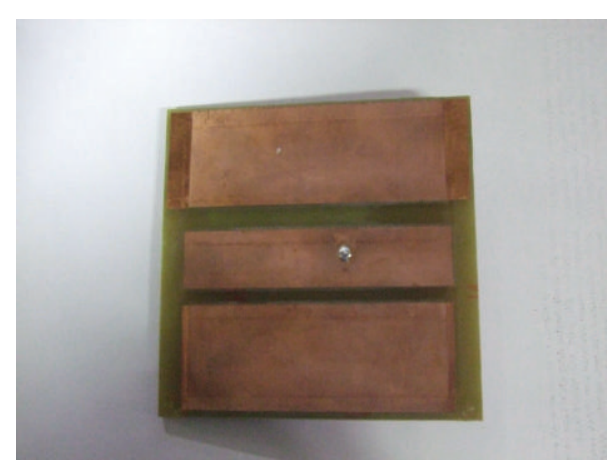

FIGURE 6: The realized broadband microstrip antenna. 


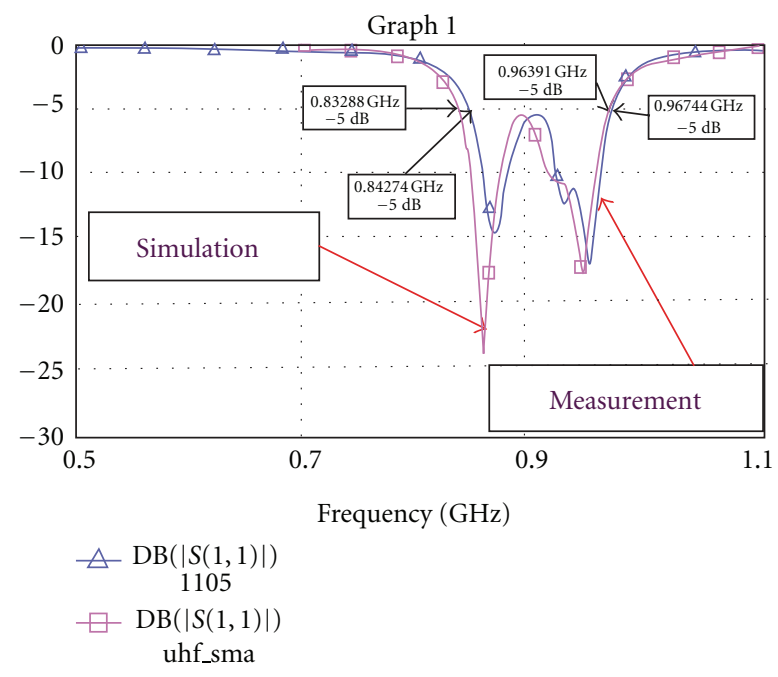

Figure 7: Measured return loss.

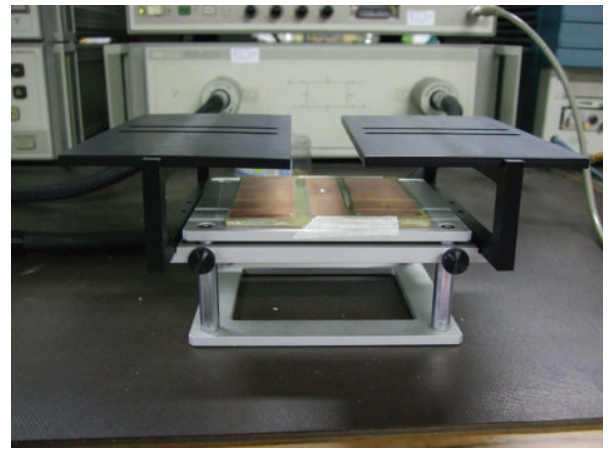

(a)

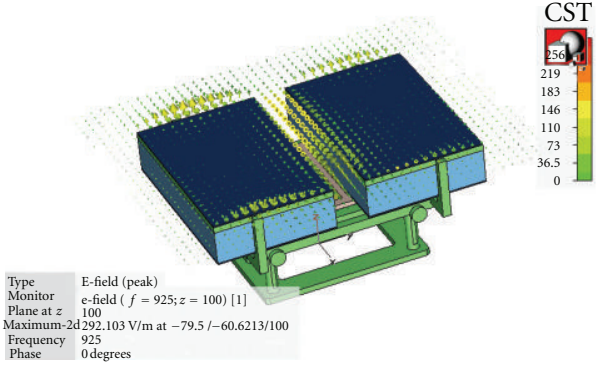

(b)

Figure 8: The laboratory fixture for testing.

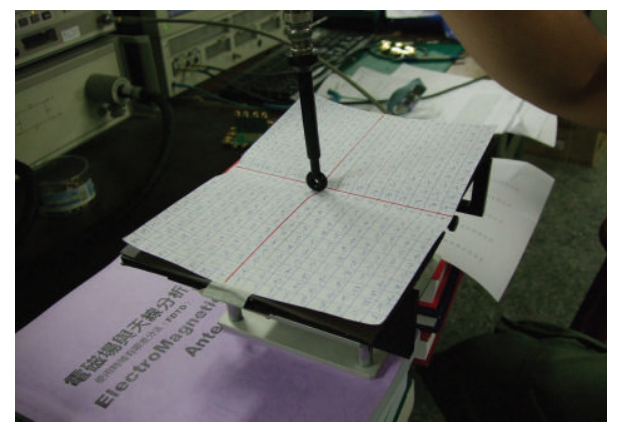

Figure 9: Measurement of the proximity field on the platform surface.

occupying not much room in machine, (b) easy to fabricate, because it can be etched on a printed circuit board (PCB), and (c) its fundamental mode [5] is naturally to have a broadside radiation pattern, which is suitable for the present application as shown in Figure 1. A microstrip antenna can be seen as a loosy resonator due to radiation [6].
However, the obvious disadvantage of microstrip antenna is its narrow band. The target bandwidth of this work is about $860 \mathrm{MHz} \sim 960 \mathrm{MHz}$ which is for covering all RFID standards worldwide. Consequently, a special design technique is necessary to have such a broadband design of microstrip antenna.

The electromagnetic package CST [7] is employed for the simulation before fabricating the antenna, which is a full 3D tool for antenna simulation. Figure 4 is the simulation model, and it is also the final determination of the geometrical and material parameters. Fr4 is used as the substrate. The central rectangle is the main microstrip antenna, whose horizontal side of $86.5 \mathrm{~mm}$ approximately follows the theoretical resonant length of half wavelength in substrate. The other upper and lower rectangles play the parasitic parts which have also strong coupling effect with the central radiator. This technique has been widely used [8] for broadening the bandwidth of microstrip antenna. However, usually, parasitic parts are set at the ends of the resonant side. Putting them along the resonant sides is a unique feature in the present work. Figure 5 shows the simulated result based 


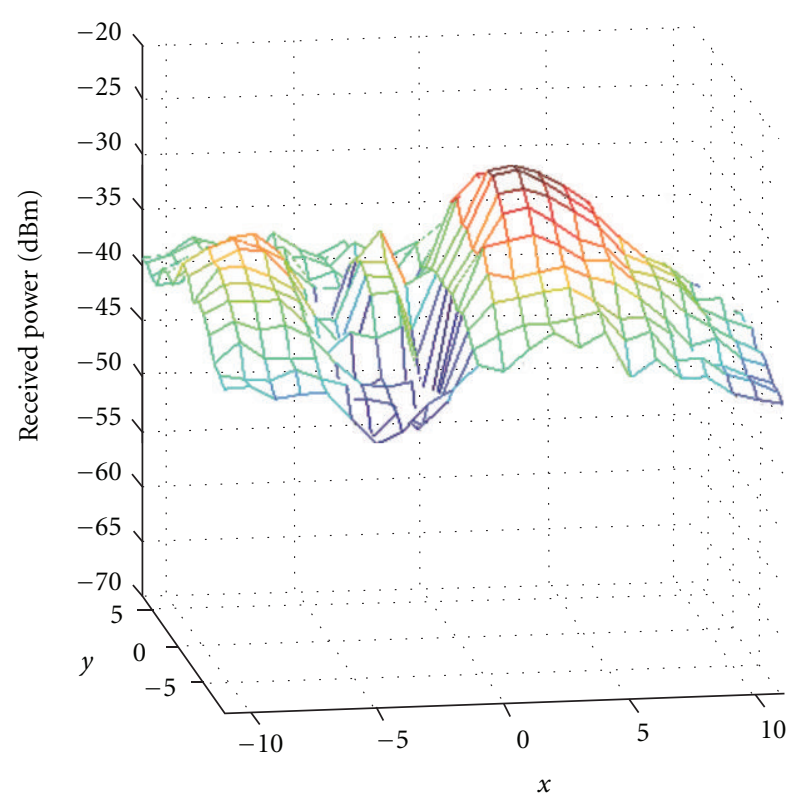

(a)

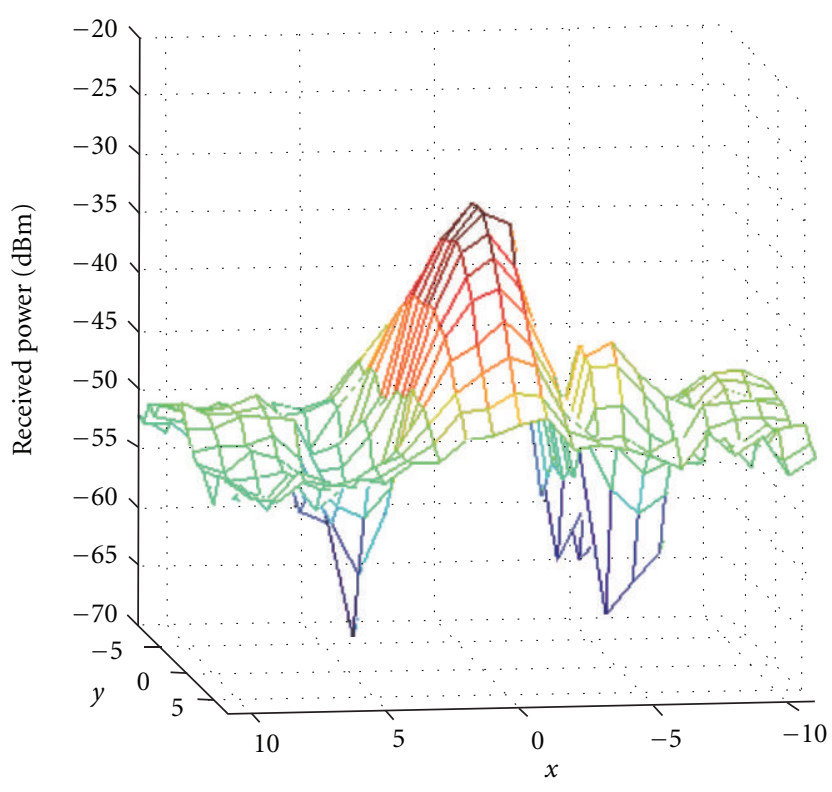

(b)

FIGURE 10: Distribution of proximity field (a) no shielding sheets, (b) sheets on and beneath the platforms.

on such an idea of broadband design. It is obvious to see the three generated modes, namely, $\mathrm{U}$ mode, $\mathrm{M}$ mode, and $\mathrm{L}$ mode are caused by the upper, middle, and lower patches displayed in Figure 4, respectively.

It should be remembered that the present design of RFID communication is a short-range one, therefore, we trade off in obtaining the broadband while scarifying the performance of return-loss response. We set the $-5 \mathrm{~dB}$ of return loss as the index for the matching condition in this design, and it predicts in simulation an $833 \mathrm{MHz} \sim 964 \mathrm{MHz}$ bandwidth as shown in Figure 5. After simulation in design, the antenna is realized by being etched on a PCB with a substrate thickness $4 \mathrm{~mm}$ as shown in Figure 6. Its measured return loss is shown in Figure 7. Referring to the bandwidth requirement again, the results both of simulated and measured ones are quite close to each other.

\section{Fixture Design for Reading}

As shown in Figure 1, in the fast process of attaching chips on the RFID tags, the moving band on which the preproduced tag antennas are being carried, is supported by a mechanical fixture. For simulating the fixture of a real machine in the laboratory, a nonmetal fixture is assembled as shown in Figure 8(a). Its top platforms are made of plastics and serve to support the tag band. Furthermore, the reader antenna designed above sits under the platforms and sits at the central position as well.

From the first idea, for depressing the response of the neighbor tags, we adopt the shielding sheets of Nanonix [9] and put them on and beneath the top platforms. The left and right sliding platforms are adjustable to find an optimal window width for antenna below to read as the purpose. Figure $8(\mathrm{~b})$ is a computational model of platform for CST simulation. The whole structure of Figure $8(a)$ is built into this CST model, including the patch antenna itself. When the reader antenna is excited, the electromagnetic field around the open window of platform can be displayed in time domain as that shown in Figure 8(b). It can be seen clearly that there is a strong field distribution inside the open window, on the other hand, the field on the platform is depressed obviously. Such a field distribution is to make the other tags which are not above the window to be not easily readable. Consequently, the aim of reading exclusively one tag only for the purpose of functional check of the whole tag when it passes the reader antenna is achieved. As expected, in one experiment in the laboratory simulating the real chipattachment process in factory, there are three tags side by side on the platform, yet only the middle one is readable because of the present design for reader antenna plus the fixture.

\section{Analysis of Proximity Field and Discussion}

For analyzing the field distribution on the surface of the platforms, a setup for the proximity field measurement is also designed. By drawing grids in advance on a paper which is fixed on the platforms, a field probe suitable for the frequency range of reader antenna is used in a way of point-by-point to measure on the surface the proximity field radiated from the reader antenna, see Figure 9.

Two configurations are under evaluation, namely, (a) no shielding sheets and (b) with shielding sheets on and beneath the platforms, simultaneously. As an example, the measurement results of $910 \mathrm{MHz}$ are shown in Figure 10. The vertical dimension is to present the received power in $\mathrm{dBm}$ on the tested surface. It should be noted that the $y$-direction in 


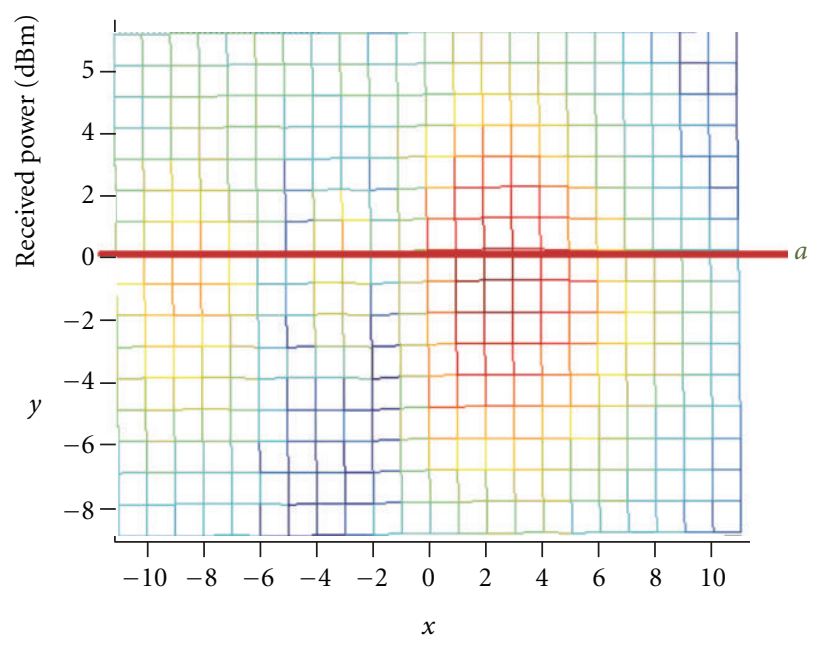

(a)

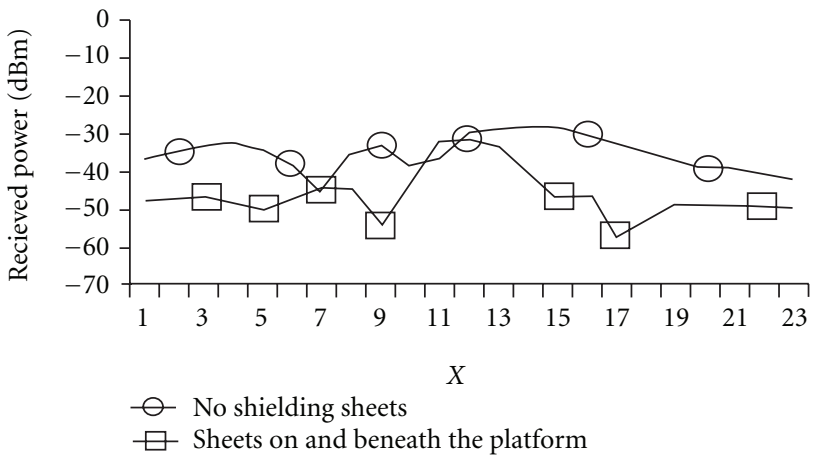

(b)

Figure 11: One-dimensional distribution of proximity field (a) line for measurement, (b) comparison with and without sheets on and beneath the platforms.

Figure 10 (same as the $x$-direction in Figure 8) on the spatial measuring coordinates is along with the long side of the open window. As expected, at the middle point of $x$-axis, the field peak does happen, namely, it occurs at the center of the open window. This is to ensure easily reading one tag only which stops at the center of the open window of the platform.

Figure 11(a) shows a two-dimensional proximity field distribution by color on the platform of fixture. For a quantity comparison of field in one dimension, along the $x$ axis and at the middle point of $y$-axis, a line is set to cross the open window on the platform, see Figure 11(a) also. The measured fields along this line of cases in Figures 10(a) and 10(b) are extracted and represented in Figure 11(b). Those two lines show that the effect of shielding sheets is indeed produced to have a higher contrast of fields for central and side parts of the window. More than $10 \mathrm{~dB}$ at least is achieved for the aim of this present work. Consequently, the field on the region of side tags is lower than that above the center of the window when the shielding sheets are applied.

\section{Conclusions}

In this paper, we have proposed a design of fixture for the machines of RFID tag production. After attaching the chips on antennas of a band of tags, this machine needs to check each tag if its chip does work or not at the end of production procedure. A broadband microstrip antenna is also designed for this fixture. By using the shielding sheets on the fixture, the requirement of reading exclusively only one tag is achieved. The proximity electromagnetic fields, which are radiated from the designed reader antenna, are measured as well on the surface of fixture platforms to evaluate the proper configuration of shielding sheets. This present work has demonstrated itself as a reference design for production machines of RFID tags, which need to have a functional check for each tag described in this work.

\section{Acknowledgment}

The Highlight Tech Corp. [10], Tainan, Taiwan, who is a company providing machines of RFID tag production, is deeply appreciated for their grant support in this project.

\section{References}

[1] K. Finkenzeller, RFID Handbook: Fundamentals and Applications in Contactless Smart Cards and Identification, Wiley \& Sons, New York, NY, USA, 2nd edition, 2003.

[2] R. Bansal, "Coming Soon to a Wal-Mart Near You," IEEE Antennas and Propagation Magazine, vol. 45, no. 6, pp. 105106, 2003.

[3] S. Sarma, D. Brock, and D. Engels, "Radio frequency identification and the electronic product code," IEEE Micro, vol. 21, no. 6, pp. 50-54, 2001.

[4] C.-F. Huang, "Low-cost solution for RFID tags in terms of design and manufacture," in Current Trends and Challenges in RFID, C. Turcu, Ed., InTech.

[5] K. R. Carver and J. W. Mink, "Microstrip antenna technology," IEEE Transactions on Antennas and Propagation, vol. AP-29, no. 1, pp. 2-24, 1981.

[6] Y. T. Lo, D. Solomon, and W. Richards, "Theory and experiment on microstrip antennas," IEEE Transactions on Antennas and Propagation, vol. AP-27, pp. 137-146, 1979.

[7] http://www.cst.com/.

[8] J. R. James, P. S. Hall, and C. Wood, Microstrip Antenna: Theory and Design, vol. 12 of IEE Electromagnetic Waves Series, 1981.

[9] http://www.nanonix.com/nanonix_china/company/index .htm.

[10] http://www.high-light.com.tw/. 

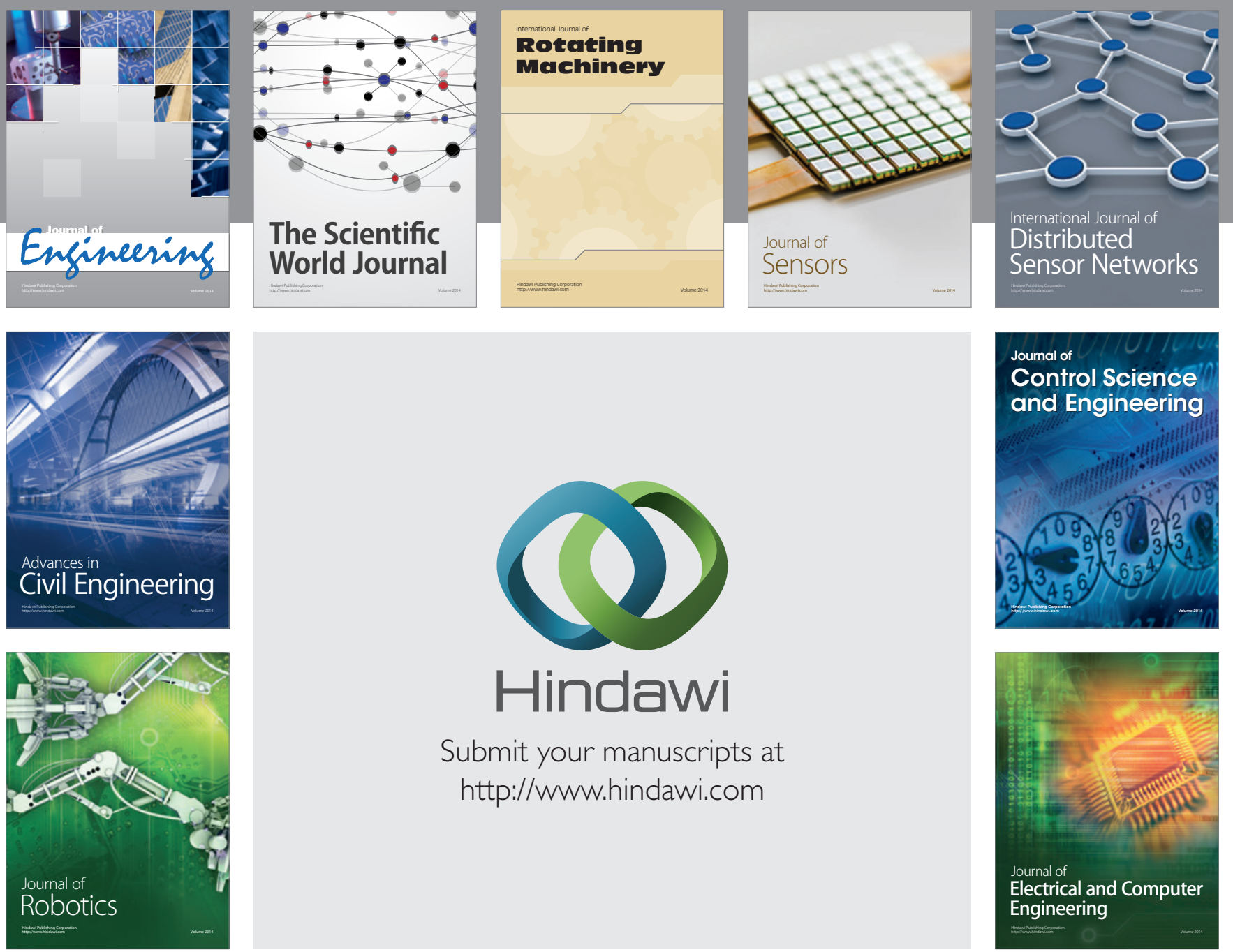

Submit your manuscripts at

http://www.hindawi.com
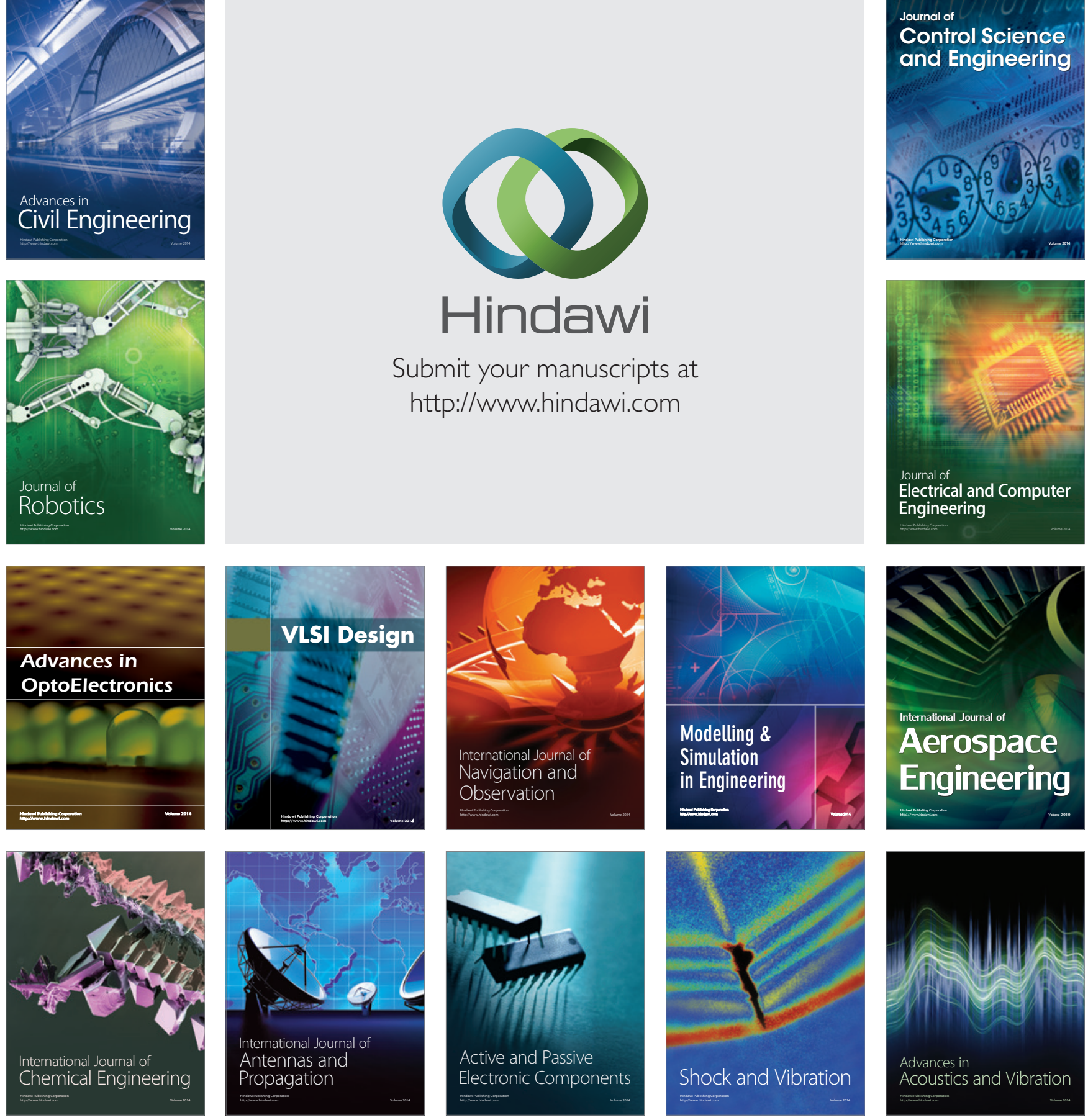